\title{
Importance of Diversified Marketing Strategies for Fast Food Restaurant Chains
}

\author{
Ekaterina Shcherbakova
}

\section{ABSTRACT}

Every organization needs to consistently adjust operations and marketing strategies in order to perpetually satisfy consumers and reinforce dedication to the vision and mission of the company. The adjustments need to be made over time, according to situational influences as well as internal and external trends affecting consumer behavior. Without a proper marketing strategy, a company may go out of business due to internal and external organizational pressures. Nowadays, as the economies of countries worldwide show signs of crisis, fast food industry players need to adjust their marketing strategies in order to overcome the competition within new circumstances. This literature review demonstrates that in order to succeed in this competition, food chain companies need to combine multiple approaches and use omni-channel marketing campaigns. This article summarizes the research made over the last two decades and suggests topics in this area that can be further researched. The research documents, reviewed in chronological order, are peer-reviewed articles, conference papers, corporate websites and major media resources.

Keywords: consumer behavior, McDonald's, decision-making process, business strategy, marketing strategy

\section{Introduction}

Modern fast food chain companies are consistently affected by the multiple internal and external pressures that force them to constantly adapt business strategies to remain competitive. The significance of adjusting marketing strategies to local tastes has been emphasized repeatedly (Bowman et al., 2003). The importance of having a variety of marketing methods for various types of customers has been highlighted since the first fast food restaurants started to expand globally in the middle of the $20^{\text {th }}$ century (Talpau \& Boscor, 2011; Vignali, 2001;). The ways to sell and distribute products have also undergone periodical adjustments, depending on the country of distribution (Sutton-Brady et al., 2010). In the food business, McCarty's concept of the 4Ps - product, promotion, place and price - played an important role in the foundation for the development of marketing strategies (McCarty, 1975). However, the more marketers worked on different approaches to the marketing mix of the $4 \mathrm{Ps}$, the more variables were added to this list. People (staff), processes (ordering, delivery, etc.) and physical experience soon became considered as parameters within the marketing mix (Gilligan \& Fifield, 1996). With the growth of competition in the market, companies had to become more and more instrumental in the development of new approaches to marketing strategies.

From 1980 to 1999, the fast food segment grew faster than any other segment of the outdoor food industry (Jekanowski, 1999). It 
continues to grow to this day. The fast food industry has a rich history of marketing, starting with the advertising of the original products (burgers and soft drinks) to the multiple celebrity endorsement campaigns, varieties of local menus and advertisements of bundle sales. However, despite the abundance of various marketing campaigns, due to the fierce competition fueled by high demand, fast food chains continue to lose market share and yield their clients to each other. For example, two of the largest fast food chains (in terms of annual revenue), McDonald's and Burger King, have been competing for the U.S and Canadian market for several decades. McDonald's, despite being almost twice as large as its rival, closed some stores in 2015-2016 while Burger King kept opening new ones (Duprey, 2017). Burger King, coming up with new mobile applications that allow for pre-orders and discounts, and McDonald's, offering more and more delivery options, are examples of fast food industry players which are competing in the same field while using different marketing approaches.

Though the above-mentioned strategies have been extensively and successfully used before, the author claims that only a complex omni-channel marketing strategy can yield players a bigger pool of loyal consumers. This article is based on extensive research, organized in chronological order to uncover the marketing methods that have been used and how they are applied to the fast food industry to determine the effectiveness of marketing efforts. The methods are described and reaffirmed with industry case examples. The author reveals the most successful applications of these methods and suggests a new way of combining them for the most efficient strategical marketing planning.

\section{Discussion}

The fast food industry originated in the United States in the first part of the $20^{\text {th }}$ century (Kara et al., 1995). Since its establishment in 1940, McDonald's, one of the oldest fast food chain restaurants, has undergone multiple marketing strategy iterations in order to expand in the United States, and eventually, overseas (Talpau \& Boscor, 2011). Its rivals, White Castle, KFC, Burger King and other major competitors followed the same route of successful and unsuccessful iterations. All the strategies used were related to one of seven different variables of the marketing mix - product, price, place, promotion, people, process, or physical experience (Feltenstein \& Latchnuth, 1983).

The promotional activities of a small to medium sized fast food restaurant traditionally start with local price promotions. Local price promotion is one of the most widespread methods to attract customers from neighborhoods (Feltenstein \& Latchnuth, 1983). This kind of promotion is focused either on the introduction of a new product or reveals a new price of a well-known product. Such a marketing strategy fuels the sales in the neighborhoods where the advertising campaign is taking place (Feltenstein \& Latchnuth, 1983).

Another marketing strategy related to price variable is focused on price promotion. It became widely spread in the 1990s, when some food chain restaurants started to attract the pricesensitive segment of consumers (Drumwright, 1992). Bundled meals were aimed to increase the average check and to encourage buyers to spend more through further repetitive purchases at a restaurant where the bundles were sold. If a consumer wanted to purchase only one product out of the bundle, the bundle meal could still be the better option if the products sold individually cost more than same products in a bundle. Here, a customer sees the benefit of spending more and getting more (Drumwright, 1992). Moreover, the perception of bundled products is different from the perception of the same products when they are unpacked and considered individually. Tversky and Koehler (1994) claim that when considering objects individually, consumers think in more depth about the characteristics of each object, like the value or the risk associated with them. However, when bundled, these products do not initiate these thoughts. Thus, fast food chains focus on the value of the products and use these peculiarities of perception to create the feeling of benefit from purchasing a bundle meal. According to Wilkie (1994), such an approach is targeting those customers who are seeking variety and those loyal customers who are looking for a better deal from their favorite fast food restaurant.

Place-oriented marketing strategies were introduced with the establishment of dine-in 
options, in the very beginning of fast food era in the 1940s (Kara et al., 1995). Later, when researchers analyzed the factors that attracted customers to spend more time and money on fast food purchases, it was revealed that the most important factors included inexpensive food and the home-away-from-home atmosphere (Kara et al., 1995).

The architectural style of the buildings and facades of the booths inside shopping malls where fast food restaurants are located is another characteristic of a physical-focused marketing strategy that yields results (Love, 1995). According to Love (1995), well-known and easilyrecognized homogenous designs and architectural styles are the factors that attract customers and add to brand recognition.

Location, as a subfactor of the place variable, is an important parameter to consider while developing marketing strategies. Traditionally, it has been considered that the best location for restaurants are the places with the maximum amount of foot traffic and dense populations (Bronnenberg \& Waithieu, 1996). That is why one can usually find famous fast food restaurants in the downtown areas of major cities around the world. However, location can be also considered together with such parameters as brand strength and price promotions. According to Bronnenberg and Wathieu (1996), when the dominant competitor, McDonald's is located next to smaller competitor, Burger King, Burger King is unable to attract McDonald's customers through price promotions. However, over time, when Burger King developed a positioning of its products which differ them that of McDonald's, then the vicinity of the larger competitor becomes beneficial for Burger King, as from this point, it can start attracting its competitor's customers through price promotions.

Unlike the homogenous strategy for architectural designs, the pricing strategy of fast food chains proved to be successful when heterogenous. After bundle meals were introduced, marketers researched the effect of price heterogeneity on consumer behavior (Bell \& Lattin, 2000). This strategy managed to get the most responses from two types of customers: price-insensitive, or those who were willing to pay more and get more, and price-sensitive, who, though wanting to save on a purchase, still feel that bundle meals were more beneficial (Bell \& Lattin, 2000). Both categories of customers confirmed through testing that they would prefer to purchase a bundle, as they wanted to get more products for a smaller additional payment.

Another approach to fast food chain marketing strategies that has been adopted by many restaurants is the promotion based on bundling meals with toys. McDonald's introduced the Happy Meal in the U.S. in 1979 (Moore et al., 2002). A meal for kids with a toy inside was targeting young consumers and their parents who would stop by McDonald's for family dinner or for a gift for their kids. Marketers claim that this promotion was based on the fact that media, peers and parents influence children's consumption patterns (Moore et al., 2002). Thus, if approved by the media and peers and purchased by parents, the Happy Meal then becomes a desirable gift and a way to fill the stomach. Though, later research demonstrated that kids who eat at fast food restaurants regularly tend to struggle with obesity and further health issues (Bowman et al., 2003). Happy Meals continue to be used by McDonald's as a very strong promotional product. However, in order to comply with local healthy policies, McDonald's later announced changes in the kids' menu. Starting from 2011, consumers can order from the new menu which provides the option of juices, milk, sliced fruits and vegetables for all Happy Meals (Talpau \& Boscor, 2011).

However, the Happy Meal case and the concerns about the quality of its contents was not the only quality concern in the history of McDonald's and fast food restaurants in general. Originally, fast food chains were praised for cheap and substantial meals which were easy to eat on the go. For decades, fast food chains successfully operated in the U.S. under the rules of the Department of Public Health. However, when the connection between obesity and fast food consumption was examined more thoroughly in 1990s and 2000s, health organizations initiated detailed research on the quality of fast food (Bowman, et al., 2003). Prior to analyzing this topic, one needs to reflect on the reason for fast food meals to be cooked and served the way consumers are used to having it. 
Supersizing has always been one of the main product-centered strategies for McDonald's and other famous fast food restaurants. For a low additional cost, buyers can get a larger portion, or can supersize their order. According to Pollan (2016), consumers tend to eat more if the portion they have is larger than average. Research by Rosenheck (2008) reveals that the majority of fast food meals contain large portions of sodium and are low in nutrients. The quality of ingredients explains the relatively low prices. Thus, from a financial perspective, it is impossible for fast food restaurants to introduce healthier ingredients without raising prices. Neither McDonald's nor its competitors can afford major changes to the recipes of their meals without substantially increasing prices. Instead, fast food companies introduced the supersizing strategy, while some efforts to introduce niche and more expensive meals failed. For instance, an introduction of the more expensive McDonald's Arch DeLuxe burger in 1996 for the sophisticated urban demographic was unsuccessful due to the contradiction to the common perception of McDonald's as an allinclusive family-friendly food company which welcomes customers of different segments, regardless their occupation, income or place or residence. The cost of this product was in contradiction to the one expected from this brand. As a result of this product marketing mistake, the company lost around 100 million dollars (McGarth, 2008).

In the last decade, in order to compete with other major rivals (e.g. Burger King, KFC), McDonald's had to shift from reliance on a product-centered strategy to a customercentered strategy. The company had to provide better service in order to attract new and retain existing customers (Talpau \& Boscor, 2011). With competitors having a similar menu, the same business models and similar promotional campaigns, it became harder for McDonald's to differentiate themselves. However, until 2011, the corporation's mission statement claimed that the company's objective was to "Promote diversity and inclusion among our employees, owner/operators and suppliers who represent the diverse populations McDonald's serves around the globe" (Talpau \& Boscor, 2011, p. 57). Thus, though the company was focused on diversity and inclusion, still customer experience was not prioritized, at least not evidenced in the statement.

Previously, McDonald's attempted to shift to a customer-centered strategy through adjusting its menu to new locations while expanding overseas, starting from the 1960s (Song et al., 2017). Though attempting to target new customers, this strategy was still focused on the products. The introduction of local menus had its ups and downs; for example, the "no-beef' menu was favorably received by the Indian audience, while the Taiwanese customers were skeptical about the traditional rice meals in McDonald's menu (Talpau \& Boscor, 2011).

Moving forward with customer-focused marketing strategies, some improvements to customer service, specifically focused around convenience. For instance, in 2015, McDonald's introduced serving custom burgers via drivethrough under the "Taste Crafted" customer program (Baertlein, 2015). Customers could choose from a variety of buns and different toppings to customize their burgers. Additionally, years later, McDonald's introduced the selfservice kiosks in 2018 which has made the ordering process faster (Rensi, 2018).

In the light of the worldwide pandemic in 2020, many major fast food chains reported an increase in sales (Klein, 2020). McDonald's has reported that $95 \%$ of its restaurants are open and provide a safe environment for serving customers and that comparable sales have improved from March to June 2020 ("McDonald's Reports April and May 2020," 2020, para.1). The restaurants were open for customers, with "to-go" and "drivethrough" options available. No dining was allowed indoors. With such an approach to customer service, the sales increase can serve as a proxy measure of the shift of fast food chain marketing strategy from product-oriented to customeroriented.

\section{Recommendations}

During the last several decades, the fast food restaurant chains have applied multiple marketing strategies in order to secure market shares, yet still, no universal recipe was discovered that could lead any of the market players to dominance in the market. However, the above-mentioned examples of major fast food 
chains in their effort to win the customer demonstrate that any effort to focus only on one or a couple of marketing channels for promotion would not bring the desirable result. The combination of different promotion strategies yields better results than focusing on one or a couple of the above-mentioned strategies (Duprey, 2017; Rensi, 2018). From what can be learned from history of marketing for fast food companies, new promotional strategies have been various and variegated as the competition became fiercer. Now, with all these marketing methods developed and applied, companies will still need guidance on how to combine these methods in order to apply a marketing mix at the exact correct time in the business lifecycle stages. Omnichannel marketing recognizes that consumers often channel hop within a given transaction among retail stores, computer, smartphones, tablets, in-store kiosks and social media sites (Berman \& Thelen, 2018). Thus, considering such a behavior, marketers use different channels in order to win the customer. However, there is no universal formula of the right mix of the channels and the amount of effort reflected in quantitative parameters that can be implemented for an overall effective marketing strategy.

More research needs to be done on how campaigns implemented through various marketing channels compliment and amplify each other, leading to desired outcomes. Also, with the emergence of different channels of online marketing, such as the Internet, social media, email, and messengers, fast food chains need to diversify marketing efforts and combine online and offline marketing. Further research can be done that can investigate the degree of influence of the combination of online and offline marketing campaigns on the sales in the fast food industry.

\section{Conclusion}

Throughout the history of the fast food industry, companies have been instrumental in applying newly invented marketing strategies in order to increase market shares and reach new segments of consumers. Successful strategies are still being used and are focused around seven variables of the marketing mix: product, price, promotion, place, people, process and physical experience. In order to successfully compete, major players not only need to shift from productoriented to service-oriented marketing strategies, but also, they need to find the best combinations of omni-channel marketing strategies in order to strengthen their brand and stand out from the crowd of competitors.

\section{References}

Bell, D. R., \& Lattin, J. M. (2000). Looking for loss aversion in scanner panel data: The confounding effect of price response heterogeneity. Marketing Science, 19(2), 185-200. https://doi.org/10.1287/mksc.19.2.185.11802

Berman, B., \& Thelen, S. (2018). Planning and implementing an effective omnichannel marketing program. International Journal of Retail \& Distribution Management, 46(7), 598614. https://doi.org/10.1108/iirdm-08-2016-0131

Bowman, S. A., $\quad$ Gortmaker, S. L., Ebbeling, C. B., Pereira, M. A., \& Ludwig, D. S. (2003). Effects of fast-food consumption on energy intake and diet quality among children in a national household survey. Pediatrics 113(1), 112-118. https://doi.org/10.1542/peds.113.1.112

Bronnenberg, B. J., \& Wathieu, L. (1996). Asymmetric promotion effects and brand positioning. Marketing Science, 15(4), 379-394. https://doi.org/10.1287/mksc.15.4.379

Drumwright, M. E. (1992). A demonstration of anomalies in evaluations of bundling. Marketing Letters, 3(4), 311-321. https://doi.org/10.1007/bf00993916

Duprey, R. (2017, March 23). Why is McDonald's suddenly losing and burger King winning? The Motley

Fool.

https://www.fool.com/investing/2017/03/23/whyis-mcdonalds-suddenly-losing-and-burger-kingw.aspx

Feltenstein, T., \& Lachmuth, J. (1983). Restaurant profits through advertising and promotion: The indispensable plan. $\mathrm{CBI}$ Publishing Company.

Gilligan, C., \& Fifield, P. (1996). Strategic marketing management. ButterworthHeinemann. 
Jekanowski, M. (1999). Causes and consequences of fast food sales growth. Food Review.

www.ers.usda.gov/publications/foodreview/jan19 99/frian99b.pdf

Kara, A., Kaynak, E., \& Kucukemiroglu, O. (1995). Marketing strategies for fast-food restaurants: A customer view. International Journal of Contemporary Hospitality Management, 7(4), 16-22. https://doi.org/10.1108/09596119510146823

Klein, D. (2020, July). Why coronavirus will spark a fast-food takeover. QSR magazine. https://www.qsrmagazine.com/fast-food/whycoronavirus-will-spark-fast-food-takeover

Love, J. F. (2008). McDonald's: Behind the arches. Bantam Books.

McCarthy, E. J. (1975). Basic marketing: $A$ managerial approach. Homewood.

McDonald's reports April and May 2020 comparable sales and provides update on COVID-19 impact to the business. (n.d.). McDonald's Corporation.

https://news.mcdonalds.com/newsreleases/news-release-details/mcdonaldsreports-april-and-may-2020-comparable-salesand/

McDonald's tests custom burger program with drive-thru option. (2015, April 29). U.S. https://www.reuters.com/article/us-mcdonaldsburger-custom/mcdonalds-tests-custom-burgerprogram-with-drive-thru-optionidUSKBN0NK1YQ20150429

McGarth, J. (2008, October 20). 5 failed McDonald's menu items. HowStuffWorks. https://money.howstuffworks.com/5-failedmcdonalds-menu-items3.htm

Moore, E. S., Wilkie, W. L., \& Lutz, R. J. (2002). Passing the torch: Intergenerational influences as a source of brand equity. Journal of Marketing,
66(2), 17-37. https://doi.org/10.1509/jmkg.66.2.17.18480

Pollan, M. (2006). The omnivore's dilemma: $A$ natural history of four meals. Penguin.

Rensi, E. (2018, July 11). McDonald's says goodbye cashiers, hello kiosks. Forbes. https://www.forbes.com/sites/edrensi/2018/07/11 /mcdonalds-says-goodbye-cashiers-hellokiosks/\#38782a446f14

Rosenheck, R. (2008). Fast food consumption and increased caloric intake: A systematic review of a trajectory towards weight gain and obesity risk. Obesity Reviews, 9(6), 535-547. https://doi.org/10.1111/j.1467789x.2008.00477.x

Song, R., Moon, S., Chen, H., \& Houston, M. B. (2017). When marketing strategy meets culture: The role of culture in product evaluations. Journal of the Academy of Marketing Science, 46(3), 384402. https://doi.org/10.1007/s11747-017-0525-x

Sutton-Brady, C., $\quad$ Czinkota, M. R., \& Ronkainen, I. (2010). International marketing. South-Western Cengage Learning.

Talpau, A., \& Boscor, D. (2011). Customeroriented marketing - a strategy that guarantees success; Starbucks and McDonald's. Bulletin of the Transilvania University of Brasov. Economic Sciences. Series V; Brasov, 4(1), p.51-58. https://www-proquestcom.proxylib.csueastbay.edu/docview/10099047 45?OpenUrlRefld=info:xri/sid:primo\&accountid= 28458

Tversky, A., \& Koehler, D. J. (1994). Support theory: A nonextensional representation of subjective probability. Psychological Review, 101(4), 547-567. https://doi.org/10.1037/0033295x.101.4.547

Vignali, C. (2001). McDonald's: "think global, act local" - the marketing mix. British Food Journal, 103(2), 97-111. https://doi.org/10.1108/00070700110383154 